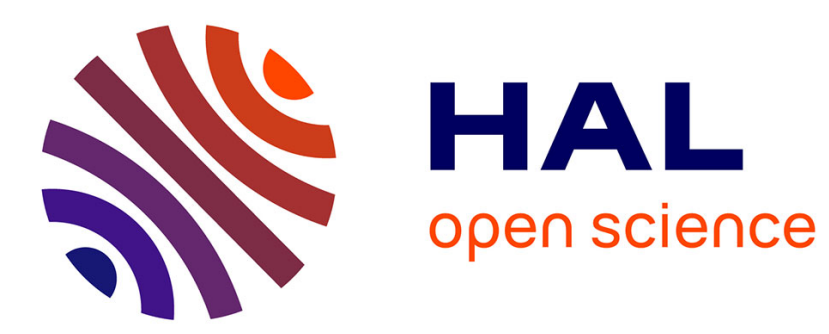

\title{
Avalanches of the Martian north polar cap
}

Patricio Becerra, Clemence Herny, Adomas Valantinas, Shane Byrne, Nicolas

Thomas, Susan Conway

\section{To cite this version:}

Patricio Becerra, Clemence Herny, Adomas Valantinas, Shane Byrne, Nicolas Thomas, et al.. Avalanches of the Martian north polar cap. 14th Europlanet Science Congress, Oct 2020, held online, Unknown Region. 10.5194/epsc2020-1093 . hal-03091591

\section{HAL Id: hal-03091591 \\ https://hal.science/hal-03091591}

Submitted on 7 Jan 2021

HAL is a multi-disciplinary open access archive for the deposit and dissemination of scientific research documents, whether they are published or not. The documents may come from teaching and research institutions in France or abroad, or from public or private research centers.
L'archive ouverte pluridisciplinaire HAL, est destinée au dépôt et à la diffusion de documents scientifiques de niveau recherche, publiés ou non, émanant des établissements d'enseignement et de recherche français ou étrangers, des laboratoires publics ou privés. 
EPSC Abstracts

\section{Avalanches of the Martian north polar cap}

Patricio Becerra ${ }^{1}$, Clemence Herny ${ }^{1}$, Adomas Valantinas ${ }^{1}$, Shane Byrne ${ }^{2}$, Nicolas Thomas ${ }^{1}$, and Susan Conway ${ }^{3}$

${ }^{1}$ Universität Bern, Physikalisches Institut, Bern, Switzerland (patricio.becerra@space.unibe.ch)

${ }^{2}$ Lunar and Planetary Laboratory, University of Arizona, Tucson, AZ, USA

${ }^{3}$ Laboratoire de Planétologie et Géodynamique, CNRS UMR6112, Université de Nantes, France

\section{Introduction}

In 2008, the High Resolution Imaging Science Experiment (HiRISE) on board NASA's MRO fortuitously captured several discrete clouds of material (Fig.1) in the process of cascading down a steep scarp of the water-ice-rich north polar layered deposits (NPLD). The events were only seen during a period of $\sim 4$ weeks, near the onset of northern spring, when the seasonal cover of $\mathrm{CO}_{2}$ is beginning to sublimate from the north polar regions. Russell et al. [1] analyzed the morphology of the clouds, inferring that the particles involved were mechanically analogous to terrestrial "dry, loose snow or dust", making the events similar to terrestrial "powder avalanches" [2]. HiRISE confirmed the seasonality of these avalanches the following spring, and has been monitoring them (Fig.2) for a total of 7 Mars Years (MY29-MY35). We will present observations from this monitoring. We seek to: (1) quantify the frequency of these events (2) quantify their effect on the mass balance of the NPLD (especially with respect to competing processes such as viscous deformation and other mass-wasting events [3-5], and (3) investigate possible trigger mechanisms.

\section{Observations}

The avalanches often appear as dense clouds of reddish, air-lofted material moving down scarps of the NPLD margins. The scarps are steep $\left(>50^{\circ}\right)$ and appear fractured (Fig.1), and the clouds themselves range in extent from just a few tens of meters to over $200 \mathrm{~m}$. Observations of many avalanche events at different stages allow us to deduce the course of a typical event. Avalanches start at a discrete point on the steep face and remain small and optically thick as they descend (Fig.1a,b). Upon reaching the basal unit they spread outward at speeds of several $\mathrm{m} / \mathrm{s}$ (measured from color fringing in HiRISE images [1]), become optically thinner, and develop a more diffuse boundary (Fig1.c,d). The avalanches then transition to near-stationary clouds close to, but detached from the scarp, which presumably slowly settle onto the exposed basal unit (Fig.1e).

A total of 57 events have been captured in action on the so-called "Discovery Scarp" (Fig.2) since the first five events were captured here in a single HiRISE image. On average, 8 events are captured on this scarp per year, and they tend to occur on its steepest sections $\left(50-70^{\circ}\right)$, and preferentially on SW-facing scarps. Figure 2 shows the location of the Discovery Scarp and all other scarps along the NPLD margins where avalanches have been observed. An average of 20 new events are observed every year. 
Avalanches have only been observed to occur between Ls $5^{\circ}$ and $70^{\circ}$, and thus are an exclusively "springtime" event. This time of year coincides with both the sublimation of seasonal $\mathrm{CO}_{2}$ ice over the north polar region, and with a peak in subsurface compressional stresses in the scarp walls, as shown by [6].

\section{Trigger mechanisms}

In accordance with the seasonality of the avalanches, trigger mechanisms to consider are (1) sublimation-driven collapse of sections of the scarp wall (material in the avalanches would most likely be a combination of $\mathrm{CO}_{2}$ and surface dust), and (2) thermal stress-driven collapse, similar to exfoliation of granitic domes on Earth [6] (material would mostly be pulverized dusty water ice, i.e. the material that makes up NPLD beds).

To examine the first mechanism, we acquired HiRISE images early in the season, before the events occurred. Images of the discovery scarp at $L_{s} 350^{\circ}$ (Fig.3a) and $L_{s} 10$ appear to show that the $\mathrm{CO}_{2}$ has already sublimated from the steepest parts of the wall by this time. However, CRISM spectra of this location (Fig.3b,c) show absorption bands diagnostic of $\mathrm{CO}_{2}$ until after $\mathrm{Ls} 50^{\circ}$. Though the bands are weak, their presence suggests $\mathrm{CO}_{2}$ persists until this time. We also used a $1 \mathrm{D}$ thermal balance model [7] to calculate the amount of $\mathrm{CO}_{2}$ frost that accumulates on a steep surface throughout the year. With conservative estimates for thermal properties (i.e., assumed an exposed wall of water ice), model results show that on a $50^{\circ} \mathrm{SW}$-facing slope, all $\mathrm{CO}_{2}$ frost has sublimated by Ls $10^{\circ}$, matching HiRISE observations but contradicting CRISM. This thermal model is extremely sensitive to dust cover on the scarp wall however, and a few $\mathrm{cm}$ of dust can accumulate, and maintain wintertime $\mathrm{CO}_{2}$. It is also possible that the steepness of the scarp makes it difficult to isolate in the CRISM data, and that the absorption bands correspond to influence from adjacent, flatter terrains.

\section{Results and Future Work}

Our study shows that north polar cap avalanches occur frequently on steep, marginal scarps of the NPLD, and likely have a substantial effect in eroding the NPLD. There are contradicting observations of $\mathrm{CO}_{2}$ frost on the steepest areas of the scarps, which we will further investigate with CRISM observations at high-roll angles that view the scarp more head-on. Even if $\mathrm{CO}_{2}$ is present in small amounts on the scarps early in the year, we have found that it is the fractured scarps that show a much higher frequency of avalanches than those that show little to no fracturing. Thus, although $\mathrm{CO}_{2}$ may be present in the clouds mixed with the avalanche material as it moves over the basal unit, a more likely trigger seems to be the springtime peak in compressional stresses that fractures the scarps [6]. In the future, we will quantify the mass wasted by the events with flow models used for terrestrial processes, and further investigate the triggers with improved detail in the thermal and stress models.
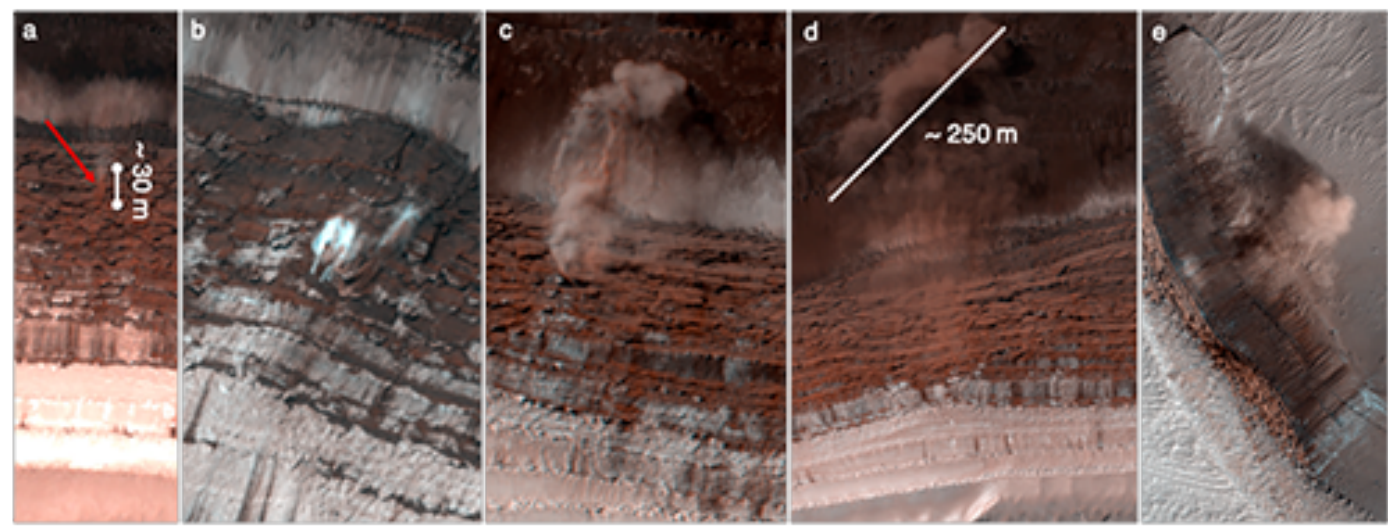

Figure 1. Various avalanches captured cascading down steep scarps of the Martian north polar ice cap. The likely stages of development of an event are shown: (a) and (b) events begin at a discrete points on the scarps (c) avatanche impacts the Basal Unit (BU) at the base of scarps (d) developed avalanche cloud advances hundreds of meters over the basal unit (e) cloud detaches from the scarp, advancing and eventually setling on the $B U$ 


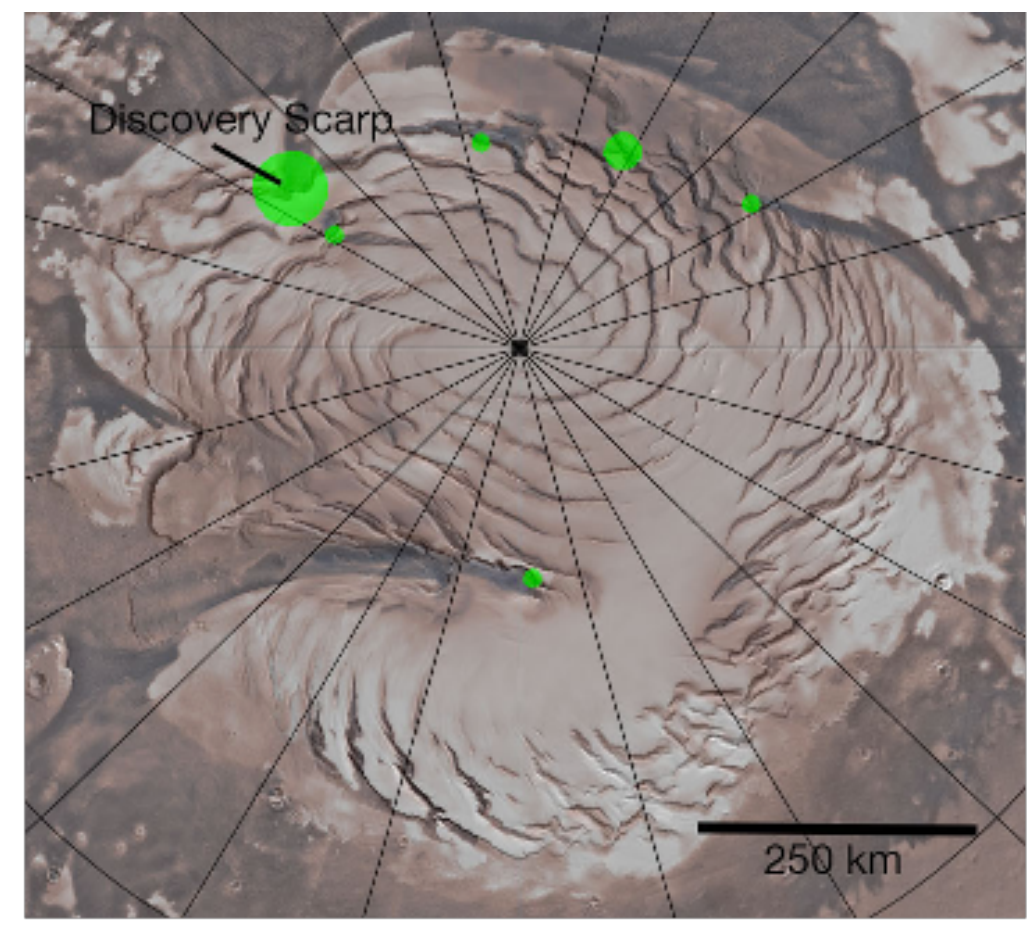

Figure 2. Map of avalanche locations on the north polar cap of Mars
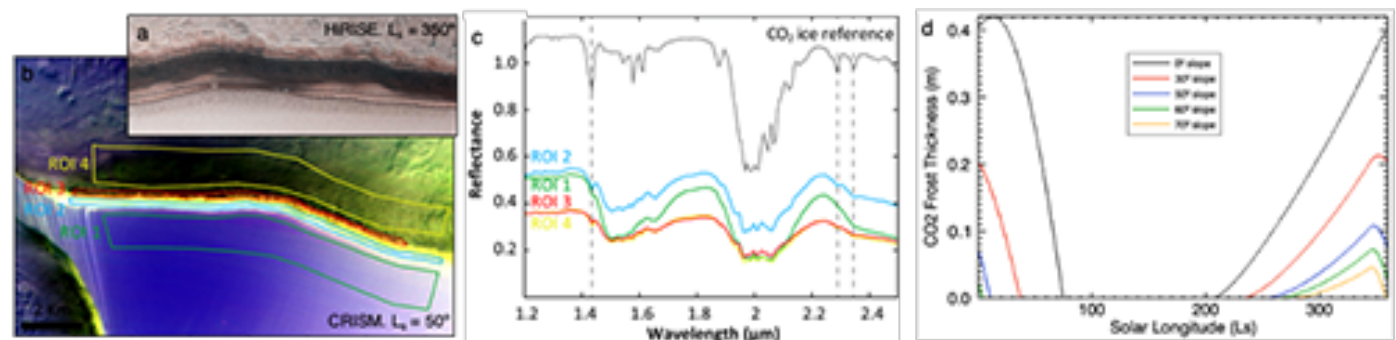

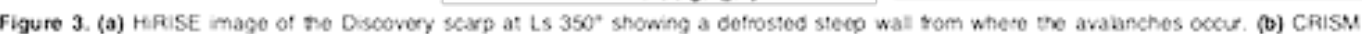
image and (c) spectra of the Discovery scarp at $L, \sim 50^{\circ}$. The doted back ine corresponds to a reterence spectum of $\mathrm{CO}_{2}$, $\mathrm{Ce}$, 5 ! Vertical dashed back lines indicate typical $\mathrm{CO}_{2}$ ice abserpton bands. (d) $\mathrm{CO}_{2}$ rost accu mulation over tme smulated by a smple energy balince model (based on [7]).

\section{References}

[1] Russell et al. (2008) GRL. 35, L23204. [2] McClung and Schaerer (2006), Mountaineers, Seattle Wash. [3] Sori, et al., GRL, 43. [4] Herkenhoff et al. (2020) $7^{\text {th }}$ ICMPSE [5] Fanara et al. 2020, Icarus [6] Byrne et al. (2016), $6^{\text {th }}$ ICMPSE [7] Dundas and Byrne (2010) Icarus 206, 716. 